\author{
Marquette University \\ e-Publications@Marquette
}

$6-2003$

\title{
The Determinants of Immigration-Policy Preferences in Advanced Economies: A Cross-Country Study
}

Joseph P. Daniels

Marquette University, joseph.daniels@marquette.edu

Marc von der Ruhr

St. Norbert College

Follow this and additional works at: https://epublications.marquette.edu/econ_fac

Part of the Economics Commons

\section{Recommended Citation}

Daniels, Joseph P. and von der Ruhr, Marc, "The Determinants of Immigration-Policy Preferences in Advanced Economies: A Cross-Country Study" (2003). Economics Faculty Research and Publications. 5. https://epublications.marquette.edu/econ_fac/5 


\section{The Determinants of Immigration-Policy Preferences in Advanced Economies: A Cross-Country Study}

By Joseph P. Daniels and Marc von der Ruhr*

This paper employs survey data to examine the determinants of immigration-policy preferences among ten advanced economies. Ordered probit specifications suggest that skill level is a robust determinant of immigration-policy preferences and that less-skilled workers are more likely to express a preference for policies that restrict immigration. The results also suggest that older individuals, members of trade unions, and those who classify their political ideology as conservative are more likely to favor limiting immigration while non-citizens are less likely to favor such policies. Individual country-level regression results vary, in particular with regard to the influence of trade union member- ship, which is a robust determinant of immigration-policy preferences for both measures of skill in only a subset of nations. (JEL FO, F2, HO)

\section{Introduction}

The process of globalization continues to be the subject of considerable debate. Controversy surrounds many aspects of globalization, including the impact that increasing trade and capital flows have on economies, the role and influence international institutions should have on national policies, and the effect of immigration policies on destination economies. Recently, particularly in Europe, policies governing legal immigration are at the center of political debate. Public views toward immigration policy are the focus of this paper.

It is a widely held belief that increased immigration decreases workers incomes in the destination country and increases unemployment among native workers [Friedberg and Hunt, 1995]. Though each concern represents a relevant economic question, popular beliefs and economic theory seem at odds with each other. In fact, most economic studies find small net gains in GDP per capita to host countries from increased immigration and that past immigration has had no obvious impact on unemployment in the host country. (For evidence and a summary of the literature, see Coppel, et al. [2001]).

This tension between the public opinion of the perceived effects of immigration on a host economy and the actual economic impact creates an interesting policy problem. On the one hand, special interest groups and non-governmental organizations are becoming more globally organized, thereby increasing their capabilities of influencing economic policy in several 
countries simultaneously [OECD, 1996]. This influence is, at least in part, based on popular public opinion. On the other hand, as suggested above, a significant portion of public opinion is inconsistent with actual economic outcomes. Consequently, there is the possibility that policies increasingly are affected by misguided opinion rather than data or theory. As a result, it is a valuable exercise to study the determinants of individual level immigration-policy preferences so economists can better understand possible sources of misinformation among the general public.

There are a number of excellent studies in the economics literature on the effects of immigration on host economies, and of immigration. Yet, as Scheve and Slaughter [2001] point out, little research has focused on the determinants of individual preferences regarding immigration policy. They argue that only after individual preferences are understood can reasonable policy-making efforts be made.

This paper extends Scheve and Slaughter's analysis of the U.S. to present new evidence on immigration-policy preferences across ten advanced economies. The data is unique in that it results from a single survey instrument employed during a given year across a number of economies. This study, therefore, contributes to the literature in a two important ways. First, it tests whether skill level--as measured by education and relative income is a robust determinant of immigration-policy preferences across a large sample of advanced economies. Second, it considers not only aggregated results across ten countries, but also examines results for reach individual country included in the sample.

The empirical examination shows that skill level is a robust determinant of immigrationpolicy preferences, that is, less skilled workers are more likely to want limits on immigration. The results also suggest that individuals are more likely to favor policies limiting immigration as they: (1) are older, (2) are members of trade unions, and (3) classify their political ideology as conservative. The results also indicate that individuals who are not citizens of their country, or whose parents are not citizens of the respondent's country are less likely to favor policies that restrict immigration. Individual country-level regression results do vary, in particular with regard to the influence of trade union membership. This last result suggests a need for further research on how political opinions and activities of trade unions vary across countries.

The remainder of the paper is organized as follows. Section two reviews pertinent literature that gauges general public opinion and explains the political economy of trade-policy preferences. Section three presents the key results of a cross-national survey, thereby describing the dependent variable of the authors' analysis. Section four describes the empirical treatment of the data and provides the results of the analysis and their interpretation. Section five offers a summary and suggestions for future research. 


\section{The Political Economy of Immigration-Policy Preferences}

The majority of research on the determinants of immigration pohcy in host countries has focused on immigration politics. This is not surprising, as migration politics historically developed along with economic development because these policies are used to influence the size and composition of the labor force.

Historically, immigration policy seems to have been influenced by labor market conditions in a given country, whereas immigrant flows have been strongly linked to labor market differences between countries. Williamson [1998] lists a series of historical events linking immigration restrictions to labor market conditions as opposed to actual immigrant flows. It initially seems understandable that an economy experiencing higher unemployment or lagging wages may restrict immigration. Friedberg and Hunt [1995], however, find that there is not much support in the economic literature to the claim that immigrants have an impact on wages and employment of residents native to the market absorbing the immigrants. Further, as mentioned in the introduction, Coppel, et al. find that most empirical research indicates small net gains in GDP per capita to host countries from increased immigration and that past immigration has no obvious impact on unemployment in the host country.

Because this analysis of individual level immigration-policy preferences extends the recent work of Scheve and Slaughter on the United States, the reader is referred to their more extensive summary of the literature and explanation of the underlying theory. The authors appeal to two common international trade theories in order to logically evaluate the likely impact of immigration on a host economy: the Heckscher-Ohlin ( $\mathrm{H}-\mathrm{O})$ model, and the specific- factors model. Both theories address the effect of increased immigration on input factors' returns in order to explain how individuals evaluate the effect of increased immigration on their income.

Following the previous work, three implicit assumptions are made in applying these models. First, it is assumed that current factor income plays a major role in how people view their own economic well-being. Second, it is assumed that native workers in an economy believe that legal immigration increases the supply of relatively low-skilled workers; a reasonable assumption to characterize the advanced economies that are considered. Finally, it is assumed that labor markets are flexible enough to allow for full employment. The role of factor payments and income can thus be specifically addressed without concern for unemployment. Given these assumptions, much of an advanced economy resident's attitude towards immigration can be credibly attributed to how an influx of labor will influence that resident's income via their factor payment.

The first theoretical framework applied is the $\mathrm{H}-\mathrm{O}$ model, which allows for interregional and intersectoral labor mobility. Consequently, the model has no geographically segmented 
labor markets within a country. The effect of immigration on wages depends on both the magnitude of immigration and the influence the host economy has on world prices. Assuming a relatively small inflow of immigrants and a relatively small economy, wages are not affected because the effect of immigrants is absorbed via changes in the mix of output produced. The change in the mix of skilled and unskilled laborers merely motivates firms to produce more of the good that uses that type of labor more intensively. With world trade, the output change is shared with the rest of the world. If the country is not large enough to alter world prices, then wages do not change.

Wages do change, however, when the country welcoming the immigrants is large enough to change world output product prices. When world output prices change, the StolperSamuelson theorem states that wages will change, as well. A relative increase in the price of an output will increase the real return to the factor used relatively intensively in the production of that output industry and reduce the real return to the other factor. Thus, the link between immigration-policy preferences and skill depends upon whether an individual believes that the inflow of immigrants will change wages. If an individual sees no such relationship, there should be no link between skill level and immigration preferences. Conversely, if the individual does expect a relationship, there will be a link.

A similar approach is taken by the second theoretical model that is applied; the specificfactors model. In contrast to the $\mathrm{H}-\mathrm{O}$ model, the specific-factors model assumes that in each sector, there exists one input that cannot migrate between sectors, thereby making it "specific" to a given sector. There is, however, another input that is freely mobile between sectors. If this model is applied to the issue of immigration, it may be assumed that skilled labor is the fixed input and unskilled labor is the mobile input. The model predicts that as the endowment of the mobile factor (unskilled labor) increases, its own real income will fall while the real income of the specific factor (skilled labor) will rise. ${ }^{1}$

Based on these theories, the leading channel by which immigration affects individuals is through its perceived impact on individuals' labor-market returns. Past work that studied immigration policies includes Goldin [1994], who finds that the U.S. House of Representatives, in 1915, was more likely to vote for immigration literacy tests (thereby lowering immigration) the lower the wage increases in various districts between 1907 and 1915. Timmer and Williamson [1998] similarly consider political actions to infer facts regarding immigration preferences. They study five countries between 1860 and 1930 and find that more restrictive immigration policies to be correlated with a lower level of unskilled wages relative to average per-capita income. Not all studies find similar results. Citrin et al. [1997] find that personal economic circumstances play a 
small role in the formation of personal opinions. Espenshade and Hempstead [1996] find mixed evidence relating skill level and immigration restrictions. Scheve and Slaughter [2001] find that less-skilled workers are significantly more likely to prefer limiting immigrant inflows to the U.S. They find no evidence, however, that the relationship between skill and immigration policy preferences is stronger in high-immigration, or gateway, communities. This paper contributes to the literature by studying individuals' preferences of immigration-policies across ten advanced economies in an effort to directly measure the impact of various demographic variables on immigration-policy preferences from a global perspective. Further, it tests the robustness of skill level as a determinant of immigration-policy preferences by employing two different measures of skill: education and relative income. Finally, this paper considers the differences in immigration-policy preferences across each individual country to compare the results with the aggregated regression results.

\section{Description of Data on Immigration-Policy Preferences in the Advanced Economies}

The data employed in this study are the results of a survey conducted and compiled by Zentralarchiv ftir Empirische Sozialforschung. The survey, which embodies the most current international survey data available on a broad range of global issues, is part of the International Social Survey Program (ISSP) and is titled ISSP: National Identity 1996. 2 This survey focuses on respondents' attitudes toward issues of national identity and international relations, and includes many demographic variables on the respondents.

\section{Description of the Dependent Variable}

Table I provides the survey item on immigration-policy preferences and summarizes the responses. The question asks for the respondent to reveal the direction of their preferences for immigration policies, yet it does not indicate what labor markets would be affected. Using this question implicitly assumes that the respondent has some understanding of the effects of immigration policy changes on their individual welfare.

Typical of research employing survey data, missing data can be problematic and the treatment of missing data is covered in the next section of this paper. It is important to note here, however, that the overall response rate to the policy-oriented immigration question exceeds 91 percent. The response rate ranges from 83 percent for Japan to over 96 percent for Australia. Figure 1 provides the number of respondents answering either, 'reduced a little" or "reduced a lot" as a percent of those responding (missing values are excluded from this chart). The figure shows that the percentage agreeing that policymakers should limit immigration ranges from more 
than 76 percent in Germany to just over 21 percent in the Ireland. The average across all of the nations in the sample is 59 percent. Hence, in this sample, there is an absolute majority in favor of restricting the number of immigrants in the respondent's country. Nonetheless, there is a great deal of variation across countries and this variation should be accounted for in an empirical study.

\section{Summary and Description of the Independent Variables}

This study is specifically designed to test the robustness of skill level as a determinant of immigration-policy preferences in the advanced economies. The authors allow for two differ- ent specifications in order to employ two possible measures of skill. Similar to the previously cited studies, one measure of skill they include is education. A second measure employed is the respondent's income relative to the national average in the respondent's country in a second model. 3 An additional test of the robustness of skill level is to include other indi- vidual characteristics related studies show to be statistically significant determinants. Age, gender, citizenship, trade union membership, and political ideology are, therefore, included as explanatory variables. (Italy, New Zealand, and Japan are excluded from the remainder of this study because the item on income was not completed in the survey.) Table 2 provides summary statistics of the independent variables.

Educations and age are measured in numbers of years; earnings is the respondent's income as a percentage of the mean value for the respondent's nation of residence; gender equals 1 for males and 0 for females; citizenship equals 1 if the respondent is not a citizen, 2 if a parent is not a citizen, 3 if neither parents are citizens, and 4 if neither the respondent or a parent are citizens, and 0 otherwise; political ideology ranges from 1 for far left to 5 for far right; trade union membership equals 1 if the respondent is a member of a trade union and 0 otherwise.

Gender is a dichotomous variable that takes the value of unity for male and zero for female. Age is a continuous variable. Citizenship examines whether the respondent and or a combination of their parent(s) is (are) citizens of the respondent's country. The variable ranges from one, indicating that the respondent and both parents are citizens, to four, indicating that neither the respondent nor one of the parents is a citizen. Previous studies are unclear as to the effect of gender on attitudes toward immigration. Based on trade policy studies, older respondents are expected to favor policies that restrict immigration. In addition, non-citizens are expected to oppose policies that restrict immigration. Political Ideology is a categorical variable that ranges from one, indicating someone who places themself at the far left, to five, indicating someone who places themself at the far right. Previous studies conclude that more conservative respondents are more likely to support immigration restrictions. Following studies of U.S. 
residents, Trade Union Membership is included as an explanatory variable. It is a dichotomous variable equal to unity if the respondent is now, or once was, a member of a trade union and zero otherwise. Previous studies conclude that trade union members are more likely to favor protectionist policies. Given the documented role of trade union membership in affecting trade restrictions in the above studies, it is expected that trade union members are more likely to favor restrictions on immigration.

The remaining variables measure the individual respondent's skill level. Education is a continuous variable measured in years. Education is expected to correlate negatively with the dependent variable. That is, respondents with higher levels of education are more likely to disagree with policy actions that restrict immigration.

Earnings is a continuous measure of the respondent's annual income in terms of the domestic currency. To create a variable suitable for cross-country comparison, the mean value of income is calculated in each individual nation. The individual respondent's income is then expressed as a percentage of the mean pertaining to their nation of residence.4lt is expected, therefore, that a relatively lower-income will correlate with preferences to restrict immigration. Finally, to capture individual country differences, a dummy variable is included for each country. ${ }^{5}$

\section{Econometric Approach and Results}

In the empirical analysis, the immigration-policy question is modeled as an ordered choice model with five possible answers as detailed in Table 1. Given that the multiple categories of responses to the survey question follow a natural order, ordered probit (OP) estimation techniques are employed, which also allows the authors to readily compare many of their results to previous literature.

\section{Missing Values}

The first difficulty lies in addressing the problem of missing values, a common problem in empirical treatments of survey data. (Missing values for the data used here can be found in Tables 1 and 2.) There are basically two approaches to handling missingness. The first approach is to omit the cases with missing values via listwise deletion. Listwise deletion, however, may result in biased estimates if the deleted cases systematically differ from the observed cases. Listwise deletion also reduces the efficiency of estimates because important information is lost.

The most common alternative to listwise deletion is to impute values for missing data. Multiple imputation does not assume that the missing data is missing at random as does listwise deletion. Rather it generates correct uncertainty estimates conditional on the data used to impute missing values. To generate data sets with imputed values for missing data, the authors use the 
EMis algorithm of Amelia: A Program for Missing Data, by Honaker et al. [2000]. The reader is referred to King et al. [2001] for a detailed description of the advantages of this approach and the EMis algorithm.

The process of imputing values involves three steps. The first step is to generate multiple data sets containing imputed values for missing data. Based on the size of the data set and following King et al., five data sets are generated for all applications in this study. The imputed values are generated using all of the observed data employed in the regression analysis as described above. The second step is to estimate a regression model for all of the imputed data sets, thereby creating multiple coefficient estimates. The final step is to combine the estimated coefficients and standard errors. Although the literature indicates a preference for regression analysis based on imputed values, estimates based on listwise deletion were also generated and are available upon request.

\section{OP Estimates}

The five imputed data sets were used to generate the OP estimates for two aggregate models and two sets of individual country estimates. The estimated parameters of the five imputed data sets were combined together and are provided below. Model coefficients are the mean estimates of the five imputed data sets. The standard errors are found by averaging the mean standard error across the five data sets and combining this value with the standard error across the five data sets, which is adjusted for the fact that the number of observations is less than infinity.

$$
\operatorname{Se}(\beta)^{2}=\frac{1}{m} \sum_{i=1}^{m} \operatorname{Se}\left(\beta_{i}\right)^{2}+\operatorname{Se}_{\beta}^{2}\left(1+\frac{1}{m}\right)
$$

where:

$$
S e_{\beta}^{2}=\frac{\sum_{i=1}^{m}\left(\beta_{i}-\bar{\beta}\right)^{2}}{m-1},
$$

and $m$ is the number of imputed data sets.

Two different aggregate models are estimated. The first, the baseline model, contains the demographic variables (age, gender, political ideology, trade union membership, and citizenship), and one measure of skill: income. To capture country specific effects on immigrationpolicy preferences, a country dummy variable is included in each model for each of the ten countries. (The dummy variables are jointly significant across all both models.) The second model replaces income with education as a measure of skill. The dependent variable in each model is the response to the immigration-policy question described in Table 1. 
Table 3 provides the parameter estimates for the aggregate models. The coefficients that are statistically significant carry their expected signs over all three specifications. Further, across all three models, age, citizenship, political ideology, and the skill level (however measured) are always significant at a 1 percent level of significance. Thus, the results imply that older individuals and individuals who view themselves as politically conservative are more likely to favor policies that restrict immigration. Individuals who are not citizens, or whose parents are not citizens of the respondent's country are less likely to favor policies that restrict immigration. Further, as skill level increases (measured by education or relative income), respondents are less likely to favor policies that restrict immigration. In the individual country regressions, the authors focus on the trade union variable. In the aggregate models the coefficient associated with trade union membership is positive and significant at a one percent level of significance in both models. Thus, trade union members are more likely to indicate a preference for policies that restrict immigration.

To better understand the impact of increases in skill on immigration-policy preferences, increases in skill level are simulated to isolate their impact on the probability that an individ- ual chooses one of the responses to the survey question detailed in Table 1. The simulation is conducted in the following manner using Clarify: Software for Interpreting and Presenting Statistical Results, Tomz et al. [2001]. First, 1,000 simulated parameters are drawn from an asymptotic sampling distribution that is multivariate normal, and whose mean is equal to the vector of parameter estimates and variance equal to the variance-covariance matrix of estimates. Next, the simulated parameters are used to calculate two sets of probabilities. First, all the explanatory variables are set at their actual value except for the measure of skill level, which is set at its median value. From this, the predicted probability of response is generated to each category of the immigration-policy question. Then, skill level is increased in value to its 90 th percentile (one standard deviation), and a second set of probabilities for each response category is calculated. The changes in these two sets of probabilities are graphically illustrated in Figures 2 and 3 . Figures 2 and 3 illustrate the fact that increases in skill level are likely to increase the probability that a respondent favors policies that increase immigration or leave immigration unchanged; and decrease the probability that a respondent favors policies that decrease immigration. It is only the degree to which these probabilities change that differs between the skill 
measures used.

Frey [1992, p. 230] argues that because empirical research has been predominately focused on the United States, it makes it difficult to determine what part of the results are due to public choice views and the part due to "particular conditions obtaining to the United States." It is important, therefore, not to generalize across countries the characteristics that influence immigration-policy preferences.

Daniels and von der Ruhr [2002] argue that, in regard to policies that restrict international trade of goods, trade union membership as a determinant of individual policy preferences cannot be generalized across countries. Their evidence leads the authors to consider whether the importance of trade union membership as a determinant of preference toward policies restricting immigration may vary over different countries. Furthermore, because the country- specific dummies were jointly significant in the previous specifications, there are systematic differences across the ten countries. Consequently, the authors are interested in examining these specifications on a country-by-country level to explore country-specific influences on immigration-policy preferences. To conduct the country-level analysis, they estimate the two models for each individual country. Again, estimates are made for each imputed data set and the coefficients and standard errors are calculated in the manner described earlier. The results are, in most respects, similar to the aggregated results. Because of space considerations, the full results are not provided here, but are available upon request. An important and interesting difference, however, is the impact of trade union membership. Table 4 provides the estimated coefficients and standard errors for trade union membership of each nation in the sample.

Table 4 shows that trade union membership is significant in the income model for Australia, West Germany, Sweden and Canada, at the 5 percent level, and for Austria at the 10 percent level. In model two (education) it is significant for Australia and Canada at the 5 percent level and for Sweden at the 10 percent level. Hence, in the aggregate specifications, trade union membership as a determinant of immigration-policy preference is primarily driven by the significance of this variable for only a subset of nations. ${ }^{6}$

Though the authors do not explore this result in greater detail here, it may have implications for the possibility of the coordination of trade union activities across nation borders. After all, if trade union members in one nation do not have the same attitudes toward immigration as trade union members in another nation, it may prove impossible to achieve international solidarity as suggested by authors such as Sebbens [2000]. They leave the issue of trade union membership as a determinant of individual preferences toward global economic policies as a recommendation for future research. 


\section{Summary and Conclusion}

A number of empirical studies on the United States show that respondents' revealed preferences for immigration-policies that restrict immigration are consistent with the HeckscherOhlin theorem. That is, respondents with higher skills oppose such policies while those with lower skills favor such policies. This paper presented survey data on preferences for immigration policies for ten advanced economies. Within the entire sample, it was found that preferences toward immigration-policies are split 59 percent in favor of reducing immigration, and 39 percent in favor of either increasing immigration or leaving it unchanged. Nonetheless, there is considerable variation in the mean response across counties. Using an ordered probit model, the authors find that respondents' skill level--as measured by education and income is a robust determinant of immigration-policy preferences in a sample of 10 advanced economies. Interestingly, while trade union membership is significant in the specifications applied to the aggregated data, individual country regressions show that trade union membership is a statistically significant, robust determinant of immigration-policy preferences only in a small number of countries.

This study, therefore, makes a number of important contributions to the existing literature. Specifically, cross-country data are presented on the general public's immigration-policy preferences and illustrate that individual skill-level is a robust determinant of immigration- policy preferences. Hence, the general results found for the United States are robust across a large sample of developed economies. Part of the gap between public opinion and the actual economic impact of immigration, therefore, is due to perceptions (arguably misperceptions) that immigration increases unemployment and reduces wages of low-skilled workers in the destination country.

Further, the authors show that conditions particular to the respondent's country of residence need to be separated from public-choice results. Specifically they provide results indicating that the influence of trade union membership as a determinant of immigration-policy preferences is unique to a subset of countries and, therefore, should not be generalized across nations. Future research should examine the determinants of immigration-policy preferences across time as well as across countries. Additionally the similarities and differences of the preferences of trade union members across countries should be further examined to determine the underlying reason(s) for differences in immigration-policy preference for trade union members in different nations. 


\section{Footnotes}

*. Marquette University and St. Norbert College-U.S.A.

1. A last approach that is discussed in the literature, but not well suited to this paper (due to limitations introduced by using the international data set we use in this paper) is the area analysis model. In this model, there is a single output market, but unlike the preceding discussion, the labor market is locally segmented. Thus, the effect on wages depends on the segment of the market in which the individual lives along with that person's skill level. The relationship between skill level and immigration-policy preferences discussed under the factor-proportions-analysis model will hold for individuals located in areas that experience the inflow of immigrants. Individuals located in areas that do not absorb the immigrants will not illustrate a link between skill level and immigration-policy preferences.

2. Independent institutions in each country collected the data for the ISSP. Neither the original collectors nor the ZENTRALARCHIV bear any responsibility for the analyses or interpretation presented here.

3. Scheve and Slaughter include occupational wage as an alternative measure of skill. O'Rourke and Sinnott [2001], however, use the International Standard Classification of Occupations (ISCO) as a measure of skill. This classification, however, does not necessarily following a logical ordering of skill. Hence, the authors do not include it as an explanatory variable here. Results of this model, however, are available upon request. The ISCO can be found on the International Labour Organization's Website at www.ilo.org/public/EngYzsh/bureau/stat/class/isco.htm.

4. This particular measure may include income from sources other than wages and salaries and, therefore, may not entirely reflect skill level. This, of course, is a caveat to the model that uses income as a measure of skill level.

5. In an alternative approach, we account for cross-country differences by including an immigration openness variable, constructed as the number of immigrants relative to the labor force in each country during the year of the survey. The results of that specification are both qualitatively and quantitatively similar to the results provided here, and are available upon request.

6. As pointed out by one referee, U.S. union member do not oppose immigration, with is consistent with the AFL-CIO [February, 2000], whose position on immigration is that "The AFL-CIO proudly stands on the side of immigrant workers. Throughout the history of this country, immigrants have played an important role in building our nation and its democratic institutions. New arrivals from every continent have contributed their energy, 
talent, and commitment to making the United States richer and stronger. Likewise, the American union movement has been enriched by the contribu- tions and courage of immigrant workers. Newly arriving workers continue to make indispensable contributions to the strength and growth of our unions."

\section{References}

Citrin, Jack; Green, Donald; Muste, Christopher; Wong, Cara. "Public Opinion Toward Immigration Reform: The Role of Economic Motivation," The Journal of Politics, 59, 3, 1997, pp. 851-81.

Coppel, Jonathan; Dumont, Jean-Christopher; Visco, Ignazio. "Trends in Immigration and Economic Consequences," OECD Economics Working Paper, No. 2842001, 2001.

Daniels, Joseph; von der Ruhr, Marc. "The Determinants of Trade-Policy Preferences in Advanced Economies: A Cross-Country Study," Working Paper, Institute for Global Economic Affairs, Marquette University, Milwaukee, WI, 2002.

Espenshade, Thomas; Hempstead, Katherine. "Contemporary American Attitudes Toward U.S. Immigration," International Migration Review, 30, 2, 1996, pp. 535-70. Friedberg, Rachel M.; Hunt, Jennifer. "The Impact of Immigrants on Host Country Wages, Employment and Growth," Journal of Economic Perspectives, 9, 2, 1995, pp. 23-44.

Frey, Bruno S. "The Public Choice View of International Political Economy," in George T. Crane and Abla Amawi, eds., The Theoretical Evolution of International Political Economy, Oxford: Oxford University Press, 1991.

Goldin, Claudia. "The Political Economy of Immigration Restriction in the United States, 1890192r', in Claudia Golden and Gary Libecap, eds., The Regulated Economy: A Historical Approach to Political Economy, Chicago: University of Chicago Press, 1994.

Honaker, James; Joseph, Anne; King, Gary; Scheve, Kenneth; Singh, Naunihal. Amelia: A Program for Missing Data (Windows Version), Cambridge, MA: Harvard University, http://Gking.Harvard.edu, 2001.

King, Gary; Honaker, James; Joseph, Anne; Scheve, Kenneth. "Analyzing Incomplete Political

Science Data: An Alternative Algorithm for Multiple Imputation," American Political

Science Review, 95, 1, March 2001, pp. 49-69.

Organization for Economic Cooperation and Development, Globalization -What Implications jor Democratic Decision Making, Available at www.oecd.org, 1996.

O'Rourke, Kevin H.; Sinnott, Richard. "The Determinants of Individual Trade Policy Preferences: International Survey Evidence," Working Paper, 2001. 
Scheve, Kenneth F.; Slaughter, Matthew J. "Labor Market Competition and Individual Preferences Over Immigration Policy," Review o] Economics and Statistics, 83, 1, 2001, pp. 133-45.

Sebbens, Trent D. "Globalization and International Trade Unions: The Working Men Have no Country," New Zealand Journal of Industrial Relations, 25, 3, October 2000, pp. 233-57.

Tomz, Michael; Wittenberg, Jason; King, Gary. Glarify: Software for Interpreting and Presenting Statistical Results. Version 2.0, Cambridge, MA: Harvard University, 2001, HTTP://gking.Harvard.edu.

Timmer, Ashley; Williamson, Jeffery. (1998), "Immigration Policy Prior to the 1930s: Labor Markets, Policy Interactions, and Global Backlash," Population and Development Review 24, 2, 1998, pp. 739-771.

Williamson, Jeffrey G. "Globalization, Labor Markets, and Policy Backlash in the Past," Journal o] Economic Perspectives, 12, 4, 1998, pp. 51-72. Zentralarchiv für Empirische Sozialforschung, ISSP 1995: National Identity, ZA Study 2880. 


\section{Appendix}

\section{Table 1: Summary of Survey Item}

Do you think the number of immigrants to (Respondent's country) should be...

\begin{tabular}{ll}
\hline Response 1 & Increased a lot \\
Response 2 & Increased a little \\
Response 3 & Remain the same as it is \\
Response 4 & Reduced a lot \\
Response 5 & Reduced a lot \\
Mean Response & 3.780 \\
Median Response & 4.000 \\
Standard Deviation & 1.030 \\
Number of Respondents & 14,601 \\
Number of Observations & 13,410 \\
\hline
\end{tabular}


Table 2: Summary Data on Independent Variables

\begin{tabular}{lllll}
\hline Variable & Mean & Median & $\begin{array}{l}\text { Standard } \\
\text { Deviation }\end{array}$ & $\begin{array}{l}\text { Number } \\
\text { Observed }\end{array}$ \\
\hline Education & 14.23 & 12.00 & 12.79 & 14,194 \\
Earnings & 99.98 & 93.19 & 67.70 & 12,076 \\
Age & 45.27 & 43.00 & 16.64 & 14,412 \\
Gender & 1.52 & 2.00 & 0.50 & 14,504 \\
Citizenship & 1.17 & 1.05 & 0.58 & 14,601 \\
Political & 3.41 & 3.00 & 1.61 & 13,000 \\
Ideology & & & & \\
Trade Union & 1.68 & 2.00 & 0.48 & 12,198 \\
Membership & & & & \\
\hline
\end{tabular}

Educations and age are measured in numbers of years; earnings is the respondent's income as a percentage of the mean value for the respondent's nation of residence; gender equals 1 for males and 0 for females; citizenship equals 1 if the respondent is not a citizen, 2 if a parent is not a citizen, 3 if neither parents are citizens, and 4 if neither the respondent or a parent are citizens, and 0 otherwise; political ideology ranges from 1 for far left to 5 for far right; trade union membership equals 1 if the respondent is a member of a trade union and 0 otherwise. 
Table 3: Ordered Probit Estimates for Models 1 through 2

\begin{tabular}{|c|c|c|}
\hline & Income & Education \\
\hline \multirow[t]{2}{*}{ Gender } & 0.019280 & -0.018265 \\
\hline & $(0.0109693)$ & $(0.0182837)$ \\
\hline \multirow[t]{2}{*}{ Age } & $0.005602^{* * *}$ & $0.002287^{* * *}$ \\
\hline & $(0.0006617)$ & $(0.0006783)$ \\
\hline \multirow[t]{2}{*}{ Trade Union Membership } & $-0.063587^{* \star *}$ & -0.058564 \\
\hline & $(0.024467)$ & $(0.0236234)$ \\
\hline \multirow[t]{2}{*}{ Political Ideology } & $0.173584^{* * *}$ & $0.171461^{* * *}$ \\
\hline & $(0.0113607)$ & $(0.0108065)$ \\
\hline Income & $\begin{array}{c}-0.001519^{\star \star \star} \\
(0.000146)\end{array}$ & \\
\hline Education & & $\begin{array}{c}-0.065681^{\text {*** }} \\
(0.003023)\end{array}$ \\
\hline Australia & $\begin{array}{c}-1.708140^{* * *} \\
(0.0653442)\end{array}$ & $\begin{array}{r}-2.555812^{* * *} \\
(0.076916)\end{array}$ \\
\hline Germany & $\begin{array}{l}0.488583^{\star \star *} \\
(0.0425602)\end{array}$ & $\begin{array}{l}0.432964^{* * *} \\
(0.0440097)\end{array}$ \\
\hline Great Britain & $\begin{array}{l}0.309215^{* * *} \\
(0.0482271)\end{array}$ & $\begin{array}{l}0.272826 * * * \\
(0.0473741)\end{array}$ \\
\hline United States & $\begin{array}{l}0.110148^{\star \star \star} \\
(0.0426958)\end{array}$ & $\begin{array}{l}0.193639^{\star \star \star} \\
(0.0422688)\end{array}$ \\
\hline Austria & $\begin{array}{c}0.021065 \\
(0.0425791)\end{array}$ & $\begin{array}{l}-0.082588^{* \star} \\
(0.0427078)\end{array}$ \\
\hline Ireland & $\begin{array}{c}-0.675490^{* * *} \\
(0.0413599)\end{array}$ & $\begin{array}{c}-0.675224^{* \star \star \star} \\
(0.0416118)\end{array}$ \\
\hline Netherlands & $\begin{array}{c}0.056738^{\star} \\
(0.0353103)\end{array}$ & $\begin{array}{l}0.103272^{\star \star \star} \\
(0.0353738)\end{array}$ \\
\hline Norway & $\begin{array}{l}0.094071^{* \star *} \\
(0.0373503)\end{array}$ & $\begin{array}{l}0.125836^{\star * \star} \\
(0.0374466)\end{array}$ \\
\hline Sweden & $\begin{array}{l}0.227148^{\star \star \star} \\
(0.0418039)\end{array}$ & $\begin{array}{c}0.193794^{* * *} \\
(0.041531)\end{array}$ \\
\hline Canada & $\begin{array}{l}-0.415431^{\star \star *} \\
(0.0359265)\end{array}$ & $\begin{array}{c}-0.248226^{\star \star \star} \\
(0.0369057)\end{array}$ \\
\hline
\end{tabular}

Standard errors in parentheses. ${ }^{* * *}$ Significant at 1 percent. ${ }^{* *}$ Significant at 5 percent. *Significant at 10 percent. 
Table 4: Ordered Probit Estimates of the Coefficient of Trade Union Membership

\begin{tabular}{lcc}
\hline & Income & Education \\
\hline Australia & $0.08253228^{* *}$ & $0.09164566^{\star *}$ \\
West Germany & $(0.04642174)$ & $(0.04633984)$ \\
Great Britain & $0.1486334^{\star *}$ & 0.07692568 \\
& $(0.0683852)$ & $(0.06888582)$ \\
U.S.A. & -0.06126222 & -0.07226052 \\
& $(0.08382202)$ & $(0.08328108)$ \\
Austria & 0.03783532 & 0.02211384 \\
& $(0.0673445)$ & $(0.0669835)$ \\
Ireland & $0.10532746^{\star}$ & 0.07289704 \\
& $(0.07476056)$ & $(0.07334856)$ \\
Netherlands & -0.02032718 & -0.05186114 \\
& $(0.08327844)$ & $(0.0808714)$ \\
Norway & 0.01032054 & 0.05483676 \\
& $(0.05988328)$ & $(0.06019534)$ \\
Sweden & -0.06159008 & -0.01948904 \\
Canada & $(0.05900978)$ & $(0.05769802)$ \\
& $0.12349572^{* *}$ & $0.09181746 *$ \\
& $(0.071512)$ & $(0.07003452)$ \\
\hline
\end{tabular}

Standard errors in parentheses. ${ }^{* *}$ Significant at 5 percent. ${ }^{*}$ Significant at 10 percent. 
Figure 1: Percentage Responding That Immigration Should be Reduced

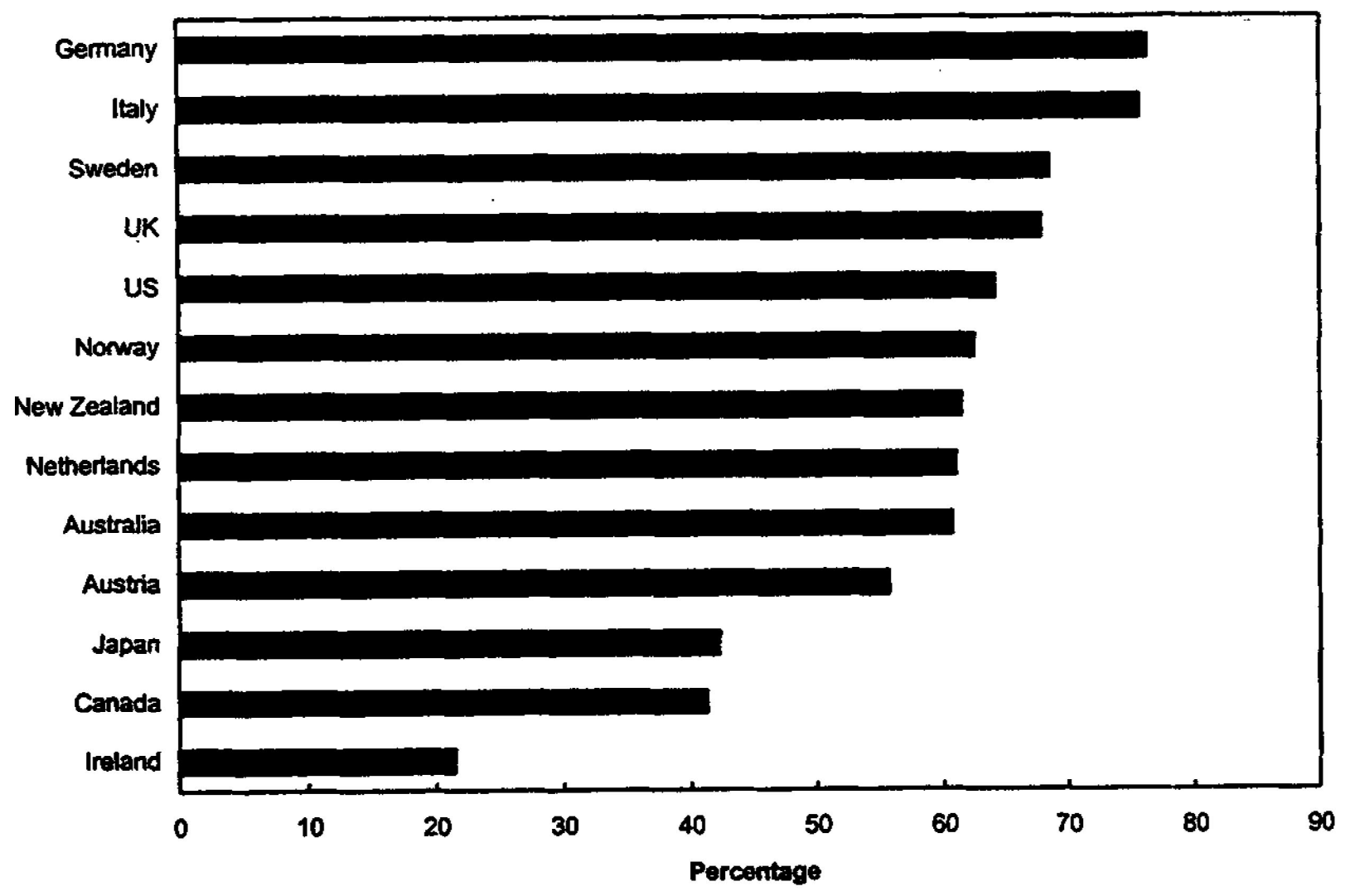

Daniels and von der Ruhr 19 
Figure 2: Change in Probability of Response to Change in Income

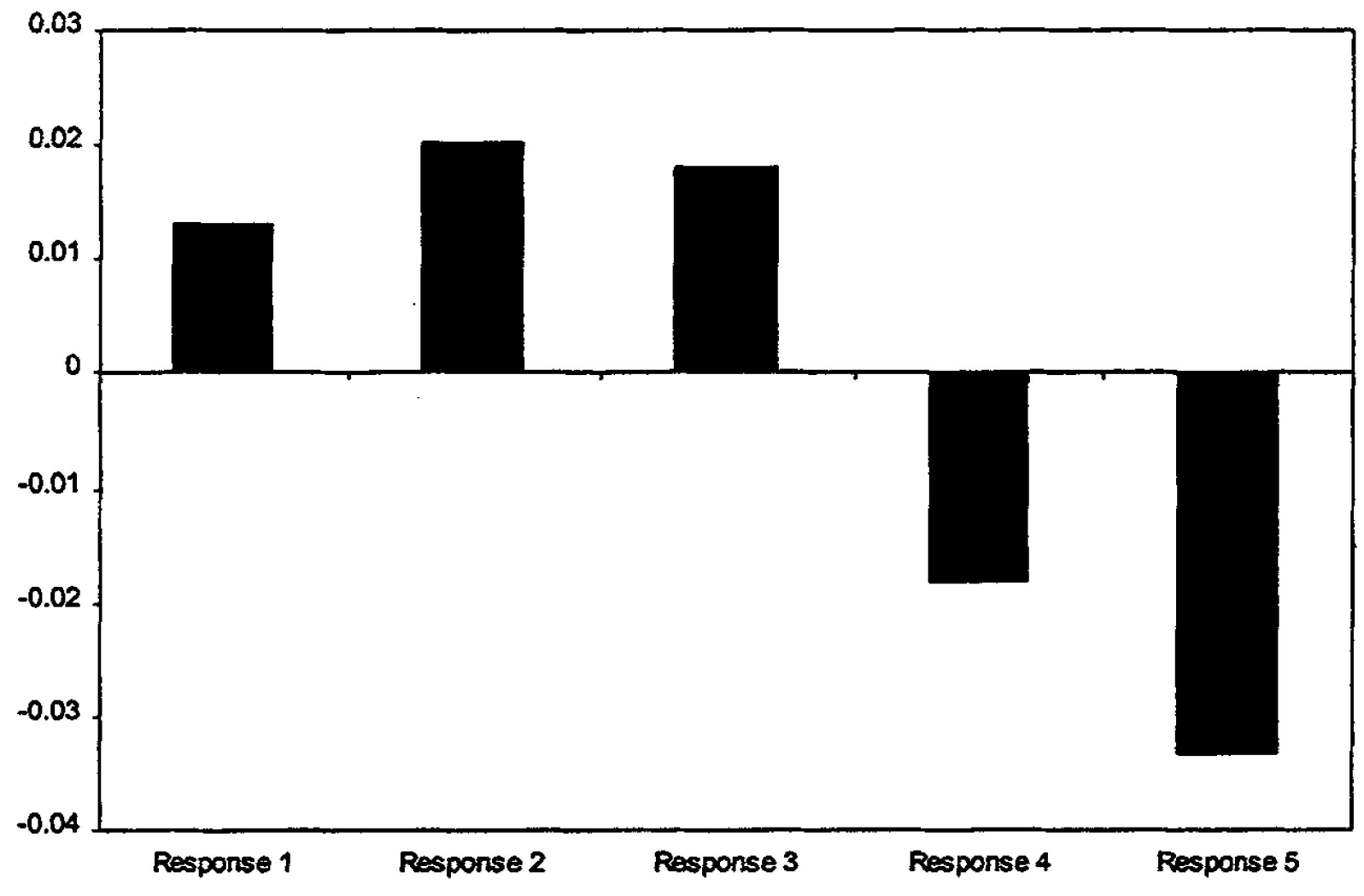


Figure 3: Change in Probability of Response to Change in Education

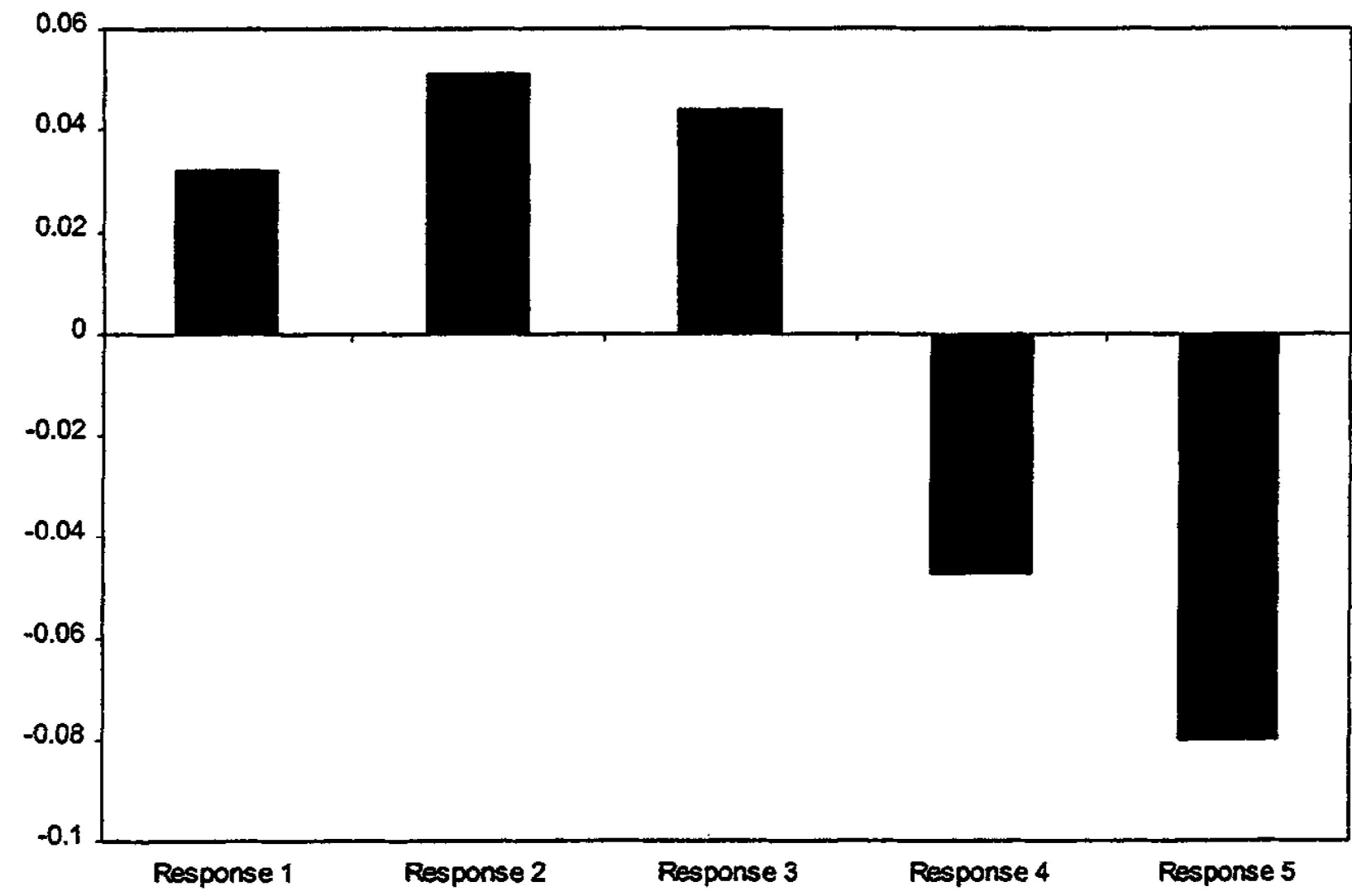

